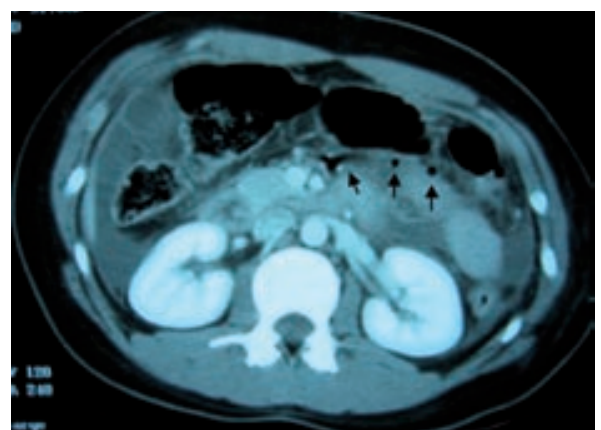

\section{BLUNT ABDOMINAL TRAUMA}

\section{Trauma services must improve}

The proposed algorithm in Jansen et al's review reiterates old dogma ${ }^{12}$ and contributes to the UK having a higher trauma death rate than most developed countries. The authors failed to discuss why and how trauma services need to improve. The incidence of major trauma is relatively low in the UK and in the absence of coordinated trauma service provision the NHS response is often enthusiastic but disorganised.

A third of the 9000-11000 deaths from trauma in the UK each year are avoidable. ${ }^{3}$ Many patients are left with long term disability. This situation has not improved since the late 1980 s, despite advances in this area.

Clinical response services should be organised from the top down. The authors missed the point when quoting statistics from the NCEPOD report on the number of junior doctors who are first attenders at polytrauma cases. ${ }^{1}$ The report was calling for a more experienced first response.

They also misunderstood some of the report's key findings and recommendations and ignored modern literature, which suggests that computed tomography (CT) and therapeutic interventional radiology are vital to investigating and managing polytrauma patients. ${ }^{4}$ Their algorithm recommends $\mathrm{CT}$ for stable patients only and ignores developments in multidetector $\mathrm{CT}$ and resuscitation facilities that put $\mathrm{CT}$ at the heart of the secondary survey. Rapid multidetector scanning is used in Europe, North America, and Australia to identify life threatening injuries and direct patients to the best treatment. Early CT scanning should be used for most patients with severe trauma, making less accurate tests, such as diagnostic peritoneal lavage, obsolete. ${ }^{5}$

This article fails to ask why trauma imaging and intervention in the UK are so far behind the rest of the world. CT's reputation as the “doughnut of death" relates to old technology and bad planning. In modern trauma centres, $\mathrm{CT}$ and angiography facilities are part of resuscitation rooms and designed to be patient and resuscitation friendly.

David 0 Kessel consultant vascular radiologist david.kessel@leedsth.nhs.uk

Anthony A Nicholson consultant vascular radiologist and clinical director, Leeds Teaching Hospitals NHS Trust, St

James's University Hospital, Leeds LS97TF

Competing interests: None declared.

1 Jansen JO, Yule SR, Udon MA. Investigation of blunt abdominal trauma. BMJ 2008;336:932-42. (26 April.)

2 Beckingham IJ, Krige JEG. ABC of diseases of liver, pancreas, and biliary system: liver and pancreatic trauma. BMJ 2001;322:783-5.

3 Royal College of Surgeons. Better care for the severely injured. 2000. www.rcseng.ac.uk/rcseng/content/ publications/docs/severely injured.html.

4 Pryor JP, Braslow B, Reilly PM, Gullamondegi O, Hedrick JH, Schwab CW. The evolving role of interventional radiology in trauma care. I Trauma 2005;59:102-4.

5 Watson NFS, Hammond JS, Brooks A, Abercrombie JF, Maxwell-Armstrong CA. Blunt abdominal trauma: note of caution on diagnostic peritoneal lavage. BMJ 2008;336:1086. (17 May.)

\section{ALL CAUSE MORTALITY}

\section{Meaningless without time frame}

What exactly does it mean to say that a treatment produces a decline in "all cause mortality by $21 \%$ " in a group of patients aged 80 and over? How long did the treatment postpone deaths from "all causes?" A month? A year? Forever?

Use of all cause mortality without a time frame stops researchers and readers asking what the treated group end up dying from. By focusing too narrowly we fail to clarify the true consequences of taking a particular treatment.

Robert W Leckridge locum consultant, Glasgow Homeopathic Hospital, Glasgow G12 OXQ

bobleckridge@gmail.com

Competing interests: None declared

1 Staessen JA, Richart T, Verdecchia P. Reducing blood pressure in people of different ages. $B M$ J 2008;336:1080-1. (17 May.)

\section{TOP-UP FEES}

\section{Not allowing top-up fees is unethical}

Bloor bases the argument against top-up fees on fairness, particularly the desire not to allow the wealthiest automatic access to the best drugs, while those who cannot pay for private care are disenfranchised. ${ }^{1}$ The flaw in this argument is that the wealthiest already access their own treatment, often exclusively in the private sector.
It is poorer patients who get caught in the "trap" of potentially being disallowed NHS care if they pay for so much as one course of treatment with a top-up drug. The greatest iniquity and inequity is surely to disallow citizens and taxpayers their NHS entitlement in the name of fairness.

These mechanical socialist arguments are propagated through a belief that people should be in charge of their own destiny but must accept what the state gives them. It is more important to be equal than be allowed to extend the quantity or quality of life. This is some 70 years behind modern political thinking in a consumerist society, where individuals are and should be in control of their bodies and destinies.

Ironically, I can find nothing in NHS legislation that disallows top-up payments, nor are top-up fees against the founding principle of the NHS. The secretary of state for health would be allowed to enable charges for certain drugs-if he so wished.

Christoph C Lees NHS consultant, Cambridge CB2 2 QQ cclees@compuserve.com

Competing interests: CCL is a founder member of Doctors for Reform.

1 Bloor K. Should patients be able to pay top-up fees to receive the treatment they want? No. BMJ 2008;336:1105. (17 May.)

\section{Top-up fairly according to means}

Many users of NHS services already top-up by paying for private care, which not only discriminates against those who cannot pay but also alleviates pressure for reform because these people would exert the most influence.

So, how to square the circle? ${ }^{1}$ Services could be categorised into three groups, which would need to be properly defined. Firstly, core services of high quality should be provided as part of the tax funded NHS. Secondly, cost effective services outside the core should still be open to all but be paid for in proportion to disposable or taxable income. ${ }^{2}$ Thirdly, services at the margins, perhaps wanted but not needed, would be funded by the individual in full. A body should be set up to identify core services and set a relative value to the others.

Alfred P J Lake consultant in anaesthesia and pain medicine Glan Clwyd Hospital, Bodelwyddan, Denbighshire LL18 5UJ apjlake@aol.com

Competing interests: None declared.

1 Bloor K. Should patients be able to pay top-up fees to receive the treatment they want? No. BMJ 2008;336:1105. (17 May.)

2 Lake APJ. Patients should pay a percentage of income. BMA News Rev 2000; January: 30. 


\section{UNNECESSARY EMERGENCY VISITS}

\section{Middle East has an answer}

The solution to the inappropriate use of emergency departments is simple-attend an emergency department with a problem more suitably treated by a GP and you pay for the privilege, in cash, at registration. ${ }^{1}$ The details can be easily worked out. All we need is politicians who are willing to take occasional decisions.

The Sultanate of Oman introduced such a charge. This encouraged patients with nonacute or minor problems to use health centres instead and had a positive effect on emergency departments.

The United Arab Emirates does much the same-emergency departments charge patients with non-acute problems double what they would pay at health centres-and it works.

Dilip J DaCruz consultant in emergency medicine, Dubai, United Arab Emirates missile53@yahoo.co.uk

Competing interests: None declared.

1 Eaton L. BMA rejects proposal that GPs should pay cost of patients' unnecessary visits to emergency departments. BMJ 2008;336:910. (26 April.)

\section{WRITING ON THE WALL FOR UNAIDS}

\section{UNAIDS replies}

England couldn't be more wrong that the AIDS epidemic is just another health problem. ${ }^{1}$

Over 60 million men, women, and children have become infected with HIV since it was first discovered. AIDS has killed 25 million people, and the epidemic still outstrips the response.

HIV was and still is an emergency requiring an unprecedented response. AIDS does not fit neatly into a health box but cuts across sectors such as education, labour, and the legal system. It involves particularly sensitive issues-sex, gender inequality, sex work, homosexuality, drug use, stigma, and discrimination.

UNAIDS was created precisely to deal with the multisectoral nature of the epidemic.

Resources for public health are desperately deficient, and this is no different for HIV. In 2006, $\$ 644$ billion was estimated to be available for all public health in low and middle income countries, of which $1.4 \%$ was spent on HIV.

Funding for HIV provides a focus and an entry point for strengthening health and social services. HIV services and treatment keep health workers alive, well, and able to work. And HIV treatment reduces admissions, freeing up health workers and valuable resources for other health care.

England's comments can only damage both the AIDS response and public health more widely. AIDS funding bolsters health systems, which provide essential services for people living with HIV, and both must be supported.
Paul De Lay director, Evidence, Monitoring and Policy Department, UNAIDS, 20 Avenue Appia,

CH-1211 Geneva, Switzerland

delayp@unaids.org

Competing interests: None declared.

1 England R. The writing is on the wall for UNAIDS. BMJ 2008;336:1072. (10 May.)

\section{Consequences of mythology}

Finally, our attention is brought to the mythology of AIDS in our community. ${ }^{1}$ In November 2007 UNAIDS reported that the AIDS pandemic was not increasing, global HIV prevalence being 33.2 million in 2007 and 39.5 million in 2006 and global HIV incidence 2.5 million in 2007 and 4.3 million in $2006 .^{2}$

The original proposition that HIV was exceptional led to such public health diversions as the use of option C by the Global Fund to Fight HIV/AIDS: procurement of products not reviewed by a regulatory authority. In 2007, of 2254 single or limited source products procured, a fifth was purchased using option C. ${ }^{3}$

The exceptionality of AIDS posited that price was the barrier on access to medicines for the poor. This ignored the incipient causes of HIV and AIDS: "The prime mover of the epidemic is not inadequate antiretroviral medications, poverty, or bad luck but our inability to accept the gothic dimensions of a disease that is transmitted sexually. Only when we cease to dodge this fact will effective HIV control be established." 4

Continuing the mythology of AIDS would be self serving to its advocates and perpetuate the dire circumstances of the poor by labelling them optional patients.

Jeremiah Norris director, Center for Science in Public Policy, Hudson Institute, 15th Street, NW, Washington, DC, 20005, USA jeannie@hudson.org

Competing interests: None declared.

1 England R. The writing is on the wall for UNAIDS. BM 2008;336:1072. (10 May.)

2 Chin I. The myth of a general AIDS pandemic: how billions are wasted on unnecessary AIDS prevention programmes. London: Campaign for Fighting Diseases, International Policy Network, 2008.

3 Global Fund. 6th Portfolio Committee Meeting, Geneva, 22-23 February 2007.

4 Sepkowitz KA. One disease, two epidemics-AIDS at 25. NEnglJ Med 2006;354:2411-4.

\section{Let's use our tools creatively}

Smallpox eradication proves that global effort on a single disease can work. Vaccine was crucial but another missing piece for HIV is reliance on a routine response to an exceptional pandemic. ${ }^{1}$ This could be fixed in two ways.

Nation to nation partnering-HIV aid too often addresses the priorities of donors and global agencies rather than recipient countries, leading to an overlapping, uncoordinated patchwork of initiatives. With no single plan or lead donor, the impact of aid is compromised, and no one accepts responsibility. Let us try partnering individual high and low income nations, perhaps with a middle income country as a third team member, to develop a single plan with a clear role for all external aid. Success could be better monitored and team members would feel a responsibility to succeed.

Centripetal programming - In Vietnam our most successful and sustainable STI/HIV clinics and outreach programmes are located furthest from large cities. However, most aid projects to improve health systems for HIV begin centrally, and many fail before they reach rural areas. Let us see whether centripetal programmes can be more successful and cost effective than those that start centrally.

Michael L Rekart director, STI/HIV Prevention and Control, British Columbia Centre for Disease Control,

655 West 12th Avenue, Vancouver, BC, Canada V5Z 4R4 michael.rekart@bccdc.ca

Competing interests: None declared.

1 England R. The writing is on the wall for UNAIDS. BMJ 2008; 336:1072. (10 May.)

\section{THE SECRET LIVES OF DOCTORS}

\section{Inspired by disease and death}

Where I grew up you were lucky to make your 10th birthday. I often arrived at school to find an empty desk, the occupier having died the night before. My grandmother was in terrible pain for two weeks before she could be transported to Ibadan, some 50 miles away, to have a simple parotid abscess drained. A man across the road fell from a palm tree and eviscerated himself. His slow death from peritonitis was the most distressing I ever saw. My cousin was in isolation for weeks, crying for companionship, after contracting smallpox -50 years later I still have nightmares about him. These were the reasons why, at the age of 7, I decided to be a doctor.

I read somewhere, "Our deepest fear is not that we are inadequate. Our deepest fear is that we are powerful beyond measure. It is our light not our darkness that most frightens us. We ask ourselves, who am I to be brilliant, gorgeous, talented, fabulous? Your playing small does not serve the world. There is nothing enlightened about shrinking so that other people won't feel insecure around you."

Martyn and some of the "great and good of medicine" are insecure people who over the past decade or so have inflicted their own disability on the profession. ${ }^{1}$ They are destroying our profession. The time has come for us to stand up to them.

Olusola O A Oni consultant orthopaedic surgeon, Leicester LE7 7WA ooni141400@aol.com Competing interests: A life dedicated to medicine

1 Martyn C. The secret lives of doctors. BMJ 2008;336:1044. (10 May.) 